\title{
BUMBA MEU BOI E ASSIMETRIA SOCIAL NO MARANHÃO
}

\section{THE BUMBA MEU BOI AND THE SOCIAL ASYMMETRY IN MARANHÃO}

\author{
Antônio Francisco de Sales Padilha*
}

\section{Introdução}

O Bumba meu Boi é uma dança dramática transversal a todo o Brasil e bastante disseminada no estado do Maranhão. Tem como enredo a morte e a ressureição do boi, representado por um Boi Boneco animado por um brincante (conhecido como miolo) que fica dentro da armação e dá-lhe vida através dos movimentos que geram a dança.

0 folguedo é baseado no seguinte mito: Catirina, esposa de Pai Francisco, o vaqueiro de confiança do dono da fazenda, está grávida e deseja comer a língua do boi preferido do patrão. Pai Francisco atende ao pedido de sua esposa e corta a língua do boi. Ao saber do ocorrido, o fazendeiro, também alcunhado de "amo", manda que os outros vaqueiros, com a ajuda dos índios, investiguem a façanha e prendam o seu autor. Pai Francisco foge para a floresta, mas os índios, conhecedores do espaço, logo descobrem seu paradeiro, prendem-no e levam-no à presença do patrão. 0 doutor "branco" é chamado para ressuscitar o boi, mas o máximo que consegue é fazer o boi mexer o rabo. 0 padre também é convocado, faz suas orações, mas nada consegue. Pai Francisco sugere que seja chamado um pajé (índio curandeiro) que mora perto da fazenda e que costuma fazer milagres. 0 pajé canta, dança, reza, invoca os encantados da floresta e consegue que o boi ressuscite. 0 fazendeiro fica feliz ao ver seu boi ressuscitado, perdoa o Pai Francisco, mas exige ser o padrinho do menino que vai nascer e, para comemorar a ressurreição do boi, manda fa-

\footnotetext{
* Doutor em Etnomusicologia e Mestre em Direção Musical pela Universidade de Aveiro PT, Bacharel em Trompete e Licenciado em Música pela UnB. Foi PhD Student na Universidade de Viena e Visiting Researcher Associate na Queen`s University de Belfast. É Professor Adjunto IV da Universidade Federal do Maranhão (São Luís/MA/Brasil). afpadilha@hotmail.com.
} 
zer uma grande festa, na qual todos dançam e cantam em volta do animal.

Ressalte-se que, mesmo sendo o Bumba meu Boi um folguedo transversal a todo o Brasil, é no Maranhão que ele se distingue por apresentar 5 diferentes estilos, denominados "sotaques": Sotaque de Zabumba, Sotaque de Matraca ou Sotaque da Ilha, Sotaque da Baixada, Sotaque Costa de Mão e Sotaque de Orquestra.

0 Sotaque de Zabumba ou Guimarães, apelidado por Azevedo Neto (1997) como "boi do negro", caracteriza-se pelo uso de instrumentos exclusivamente percussivos (tambores) e pela dança organizada em formato de roda.

0 Sotaque de Matraca ou Sotaque da Ilha, assim denominado por ter sido originado na ilha de São Luís, é caracterizado pelo uso de pandeirões e matracas, pela dança, que também se dá em formato circular, e pela presença do caboclo de pena, personagem que simboliza o índio que procurou o Negro Chico. Esse sotaque é considerado por Azevedo Neto (1997) como o "boi do índio".

o Sotaque da Baixada, por sua vez, apresenta os mesmos instrumentos do Sotaque da Ilha, mas com menores dimensões, o que resulta em um panorama sonoro menos intenso. Sua dança também é organizada em formato circular. Caracteriza-se ainda pela presença do Cazumbá, personagem que representa os seres encantados da floresta.

0 Sotaque Costa de Mão é assim denominado pelo fato de os seus tocadores percutirem os instrumentos (caixas) com as costas das mãos.
Por fim, há o Sotaque de Orquestra que, diferentemente dos anteriores, apresenta uma orquestra, composta por trompetes, trombones, saxofones, banjo e percussão, e uma dança em fileiras, lembrando a quadrilha francesa. Esse, segundo Azevedo Neto (1997), é o "boi do branco".

Ao longo deste trabalho ${ }^{1}$, procurarei articular dois tipos de preocupações: (1) a definição do Bumba meu Boi enquanto prática performativa associada ao Maranhão e à sua história; e (2) como o Bumba meu Boi, por meio dos seus múltiplos sotaques, mas em particular por meio daquele hoje denominado Boi de Orquestra, pode representar um espelho das relações políticas e intersubjetivas encontradas no Maranhão.

A articulação dos diferentes tipos de informações que reuni, centrada nas pesquisas histórica e de campo, em diálogo com a minha experiência enquanto testemunha, brincante, músico e agente político, ofereceu-me uma condição privilegiada para entender o lugar que o Bumba meu Boi ocupa hoje e ocupou no passado na construção de mundos comuns, enquanto território de identifıcação, representação e reconhecimento dos diferentes sujeitos, enquanto espaço de conflito, de conciliação e de resistência, além de objeto de controle, regulação e vigilância.

Nesse contexto, uso as propostas de Arendt $(1958,2007)$ sobre o modo como os sujeitos se fazem representar em contextos de subjugação e de Rancière (2006) sobre dissenso e política do sensível, sobretudo no que diz respeito à forma como podemos

1. Este trabalho, em parte, origina-se de minha tese de doutorado intitulada "A Construção Ilusória da Realidade, Ressignificação e Recontextualização do Bumba meu Boi do Maranhão a partir da Música” defendida em junho de 2014 junto ao Programa de Pós-Graduação em Música da Universidade de Aveiro-Portugal, sob a orientação acadêmica e intelectual da Professora Doutora Suzana Bela Sardo, a quem agradeço pelos inestimáveis apoio, contribuição, sugestão e acompanhamento minucioso. 
entender a construção de convergências entre universos subjetivos divergentes. Uso, igualmente, as ideias de Berger e Luckmann (2003) sobre o modo como a realidade é socialmente construída a partir de um mundo de ações intersubjetivas em que cada sujeito participa juntamente com os outros. De acordo com os autores, a realidade é um conceito altamente individualizado que depende do conhecimento que cada sujeito tem ou mostra ter sobre a sua própria e a dos outros. É entendida “como uma qualidade pertencente a fenômenos que reconhecemos terem um ser independente de nossa própria volição (não podemos "desejar que não existam”)", ao passo que o conhecimento é pelos autores definido como "a certeza de que os fenômenos são reais e possuem características específicas” (idem, 2003, p. 11).

Lanço mão também das ideias de Turner (1974, 1987, 2008) sobre ritual, definido a partir da "performance social" (ações de caráter religioso) e da "performance estética” (encenações e ações teatralizadas de representação individual e coletiva), já que o Bumba meu Boi representa, de certa forma, a dramatização do que é contínuo na comunidade, seguindo uma vontade e uma simbologia que não estão estabelecidas em um manual cultural, pois a sua teatralização rompe com as formas tradicionais de representação do mundo e coloca em cena as contradições e divergências da estrutura social vigente.

Faço uso, ainda, das reflexões de Turino (2008) sobre a fenomenologia da performance, na medida em que o autor faz uma clara distinção entre performar para si (performance participativa), quando o Bumba meu Boi assume a função de ritual e de instrumento simbólico através dos quais os limites da comunidade maranhense são afırmados e reforçados, e performar para os outros (performance apresentiva), quando a dança é apresentada para terceiros (uma plateia formada por turistas, por exemplo).

Importa, então, perceber de que forma todos esses argumentos se articulam, no sentido de entender o que o Bumba meu Boi, em particular o Sotaque de Orquestra, representa hoje no Maranhão, e até que ponto ele é, também, uma metáfora da sociedade que o gera e que ele próprio constrói enquanto realidade e conhecimento. Parto do princípio teórico segundo o qual o Sotaque de Orquestra é hoje um território simultaneamente de diálogo, de inclusão e de disfarce que permite aos seus performers definirem um lugar de interlocução interna e externa e aos agentes políticos garantirem a manutenção da autoridade (PADILHA, 2014). Nesse sentido, cumpre analisar o Bumba meu Boi a partir de três enunciados de identificação: o da performance, o da história e o da política.

\section{0 Bumba meu Boi enquanto território de identificação de diferentes sujeitos}

Se atentarmos ao enredo do Bumba meu Boi, verificamos que ele se define, representa e pode ser entendido enquanto um espaço de encontro entre os diferentes sujeitos que habitam o Maranhão. 0 enredo, construído em momentos históricos singulares que a dimensão da oralidade não permite localizar, inclui diversos tipos de significados. Desde logo, identifica indivíduos e os seus protagonismos.

No enredo, estão presentes os alegados donos das terras (os colonos brancos), os filhos da terra (os nativos índios) e os trabalhadores das terras (os escravos negros). Cada um é representado pelo modo como regula o mundo que comparte: os brancos 
pelo poder que exercem sobre a vida dos outros, os índios pelo modo como comandam as forças da natureza e os negros, escravos, pelo poder que a subalternidade lhes oferece de causar o dissenso. A articulação entre esses três mundos/realidades é também uma forma de inverter relações de hierarquia e de oferecer um lugar digno a cada protagonista. Cada um tem o seu papel na narrativa do enredo que, neste caso, oferece aos subalternos uma voz de decisão que a vida, para além do enredo, não autoriza. 0 enredo é, assim, um lugar catártico que permite aos seus protagonistas, representados pelos personagens ficcionais, libertarem-se da sua condição de indivíduos subjugados, nem que essa libertação dure apenas os momentos em que a performance acontece.

A performance, por seu lado, era, no passado, a forma visível de concretização da catarse. Na verdade, o modo como o Bumba meu Boi acontecia consistia em um ato de performance participativa (TURINO, 2008) que, de alguma forma, representava também perigo para a manutenção da ordem local. A documentação histórica consultada, inscrita sobretudo em notícias de jornal e autos policiais, mostra bem o modo como o Bumba meu Boi representava um momento de fragilização da autoridade colonial e branca, a qual, por meio da força da proibição e da punição, procurava interditar ou, pelo menos, controlar o seu acontecimento, mantendo-o distante dos espaços tidos como "civilizados".

Também aqui, o Bumba meu Boi define um espaço de identificação e reconhecimento. Quem o praticava habitava um lugar marginal e, como tal, estava interdito de poder ascender a espaços privilegiados onde, enquanto performer, sua subalternidade poderia estar disfarçada e seu protagonismo seria revertido a partir de uma ou- tra visibilidade. 0 performer é também um ator que, no ato da performance, adquire um lugar central. Ora, a centralidade não é - e nunca foi - um território associado aos negros e aos índios na cultura do $\mathrm{Ma}-$ ranhão. Por essa razão, os mecanismos de controle usados pela autoridade no passado procuravam também regular essa aparente possibilidade de reversão.

Dessa forma, o Bumba meu Boi, seja sob o ponto de vista do enredo, da performance, da história ou do lugar político, é um efetivo território de identificação/reconhecimento para os diferentes sujeitos que nele e sobre ele atuam. Todos estão representados, e não apenas simbolicamente enquanto membros da sociedade vigente, mas também no que diz respeito ao papel que cabe a cada um dos sujeitos na mesma sociedade. Aqui, encontramos, no passado e também no presente, hierarquias que parecem incontornáveis (os bem nascidos e os mal nascidos), tentativas de construção de poderes contra-hegemônicos (o enredo interpela o poder do colonizador), relações de racialidade (estão presentes o negro, o índio e o branco) e processos de regulação (controle e vigilância por parte de aparelhos ideológicos exógenos). À luz da análise proposta por Dwight Conquergood (2002), o enredo é uma representação da vida real, mas, também, uma expressão de desejo e uma confırmação de poder: o desejo de que a voz dos subalternos possa ser ouvida e, mais especificamente no caso do Bumba meu Boi, a "concretização" do poder da natureza indígena sobre o poder dos homens brancos alienígenas. Desse modo, a performance é o momento possível para a consagração dessa reversibilidade dos poderes que a vida real parece não permitir que se realize. 


\section{0 Bumba meu Boi enquanto espaço de conflito, de conciliação e de resistência}

0 enredo do Bumba meu Boi registra relações sociais marcadas por comportamentos ao mesmo tempo conflituosos e conciliadores, mediados por processos de evidente resistência. Na verdade, no enredo está expressa a história dramática da colonização, marcada por atitudes genocidas que fizeram coincidir com o Renascimento Europeu uma devastação étnica nos territórios colonizados. Tal como refere Walter Mignolo (2001), enquanto os europeus descobriam o que designavam por "Novo Mundo", as comunidades nativas do continente americano conheciam também o início do fim de sua possibilidade de sobreviver. Nas terras que eram suas, guardavam, porém, o privilégio de saber como se relacionar de forma harmoniosa com a natureza que as acolhia. A "cultura da pedra" trazida pelos portugueses para o Brasil, caracterizada por uma lógica que penaliza as pessoas em função dos bens materiais que a elas devem sobreviver, conflitava, portanto, com a cultura do espírito, baseada numa visão de vida e de mundo enquanto um ciclo permanentemente em transformação e em reciclagem. Esse conflito entre colonizador e colonizado, sobejamente documentado em múltiplas fontes históricas e arquivísticas, está também expresso no enredo do Bumba meu Boi, o qual, no entanto, abre um caminho conciliador no momento de crise em que os poderes nativos se sobrepõem a poderes coloniais e dialogam com eles.

0 enredo do Bumba meu Boi expressa justamente o que entre colonizador e co- lonizado existe de mais assimétrico: a relação com a natureza e a espiritualidade, mostrando de forma metafórica que a "validade dos deuses" não é universal. Nesse sentido, o Bumba meu Boi é também uma expressão de anticolonialismo, uma forma de arquivar, na performance, uma intenção política que a assimetria do poder não permite concretizar.

Metaforicamente, a articulação entre pajé e colonizador, mediada pelo escravo, é um claro sinal de que a conciliação é possível. No momento em que o colonizador aceita o mundo do indio, estabelece também uma interação entre os diferentes mundos, mostrando que eles permanecem e podem coexistir. Ou seja, a ação colonizadora teve uma eficácia relativa, pois sua tentativa etnocêntrica de homogenizar o mundo foi apenas parcialmente conseguida. Por conseguinte, no momento da conciliação, o enredo é também um testemunho de uma história de resistência igualmente inscrita nas ações do escravo; ele, outrossim, desafia o poder do seu patrão, dono da fazenda e de sua própria vida (paradoxalmente, o patrão é designado por "amo" no enredo), optando por acompanhar sua mulher e seu filho em detrimento da submissão a que está obrigado pela sua condição de escravo. 0 enredo mostra que, no momento da opção entre a obediência ao amo e o atendimento à sua companheira, o escravo demonstra que a natureza humana não pode ser amputada da sua mais importante condição de humanidade: a liberdade. Foi essa força de resistência que ofereceu ao Bumba meu Boi a possibilidade de sobreviver a todas as proibições e perseguições policiais.

2. A cultura da pedra (do homem branco) é um termo utilizado para se referir à cultura que prioriza os bens econômicos, com valor de troca, e que devem sobreviver ao seu possuidor; ela é antagônica, portanto, à cultura que prioriza as coisas do espírito e da natureza (cultura do índio). 
Com efeito, a história de sua performance está marcada também pelo conflito estabelecido com a sociedade maranhense, para a qual o enredo representa, simbolicamente, um testemunho que pode desestabilizar a ordem social vigente. 0 Bumba meu Boi foi - e, de alguma forma, continua a ser uma prática perturbadora para a sociedade estratificada do Maranhão sob o ponto de vista racial e do acesso aos bens econômicos e à educação formal. A estratificação social desse estado gerou uma elite de "cultura europeia” (ou, pelo menos, próxima dos paradigmas considerados europeus por essa elite), que culminou em uma classe alta profundamente letrada (CORRÊA, 1982) e que, historicamente, optou por uma espécie de atitude de "ignorância" em relação à realidade local que lhe era aparentemente alheia. No momento em que essa realidade se tornou visível, transformou-se também numa realidade temida. Por essa razão, a performance do Bumba meu Boi era igualmente geradora de conflito com a sociedade hegemônica que apenas a tolerava se ela ocupasse um espaço físico distante do seu.

\section{Os mediadores e o papel exercido pelo Bumba meu Boi de Orquestra num contexto de controle, regulação e vigilância na cons- trução de mundos comuns}

O Bumba meu Boi é, desde 2011, patrimônio imaterial do Brasil e representante icônico do Maranhão. Essa alteração abissal, que o transformou de uma prática proibida numa prática representativa de todos os maranhenses e da nação brasileira, aconteceu a partir de múltiplos e complexos processos de controle, regulação e vigilância.

O Bumba meu Boi foi objeto de controle, como pude constatar ao acessar a lei $\mathrm{n}^{\circ} 1.138$ de 21 de agosto de 1876 :

Figura 1 - Proibição de danças populares

Postura municipal - loi sanceionada e ji está publicada a lei $n .1138$ de 21 de agosto de 1876, sohre casas de curancleiras, que é do theor seguinte:

Art. $10^{\circ}$ Ninguem poderá receber em sua casa. 110 recinto desta capital, pessoas acommettidos de molestias contagiosas.

Os duentes nestas circumstancias deverão ser tractailos nos hospitaes. ou casas destinadas pelo presidente da provincia. Na falta porem, de predios on estabelecimentos apropriados para este mister. será permittido tratal-os em casas situadas n's suburbios da cidade e com assistencia de medicos ruspon. saveis pelos factos que occorrem, e tนฮ̄o por curandeiros. Aos contravontores a multa de trinta mil reis e oito dias de prisão.

Art. 2." Ficain prohibidas nesta capitai as dansas denominadas vulgarmente caboclos. congo. buinba, chegancia e outros fulguedos pofulares da mesma esipesie sem provia li. cença da catnara inunicipal da capital.

Aos contraventires a multi de seis mil reis. o dobro na reincidencia e oito dias de prisão.
Art. $2^{\circ}$ Ficam prohibidas nesta capital as dansas denominadas vulgarmente caboclo, congo, bumba, chegança e outros folguedos populares da mesma espécie sem previa licença da câmara municipal da capital.

Aos contraventores a multa de seis mil reis, o dobro na reincidência e oito dias de prisão.

Fonte: Diário do Maranhão em 25 de agosto de 1876. Ed.915, Anno VII. 
Assim, foi uma prática tolerada, mas regulada por normas instituídas pelos poderes constituídos. Essa situação de controle, regulação e vigilância permaneceu até a década de 1960. Até ser reconhecido como bem cultural representativo do povo maranhense, o Bumba meu Boi passou por um processo gradual de absorção por parte tanto dos poderes constituídos quanto da elite intelectual maranhense.

Figura 2 - Convite para festa com Bumba meu Boi

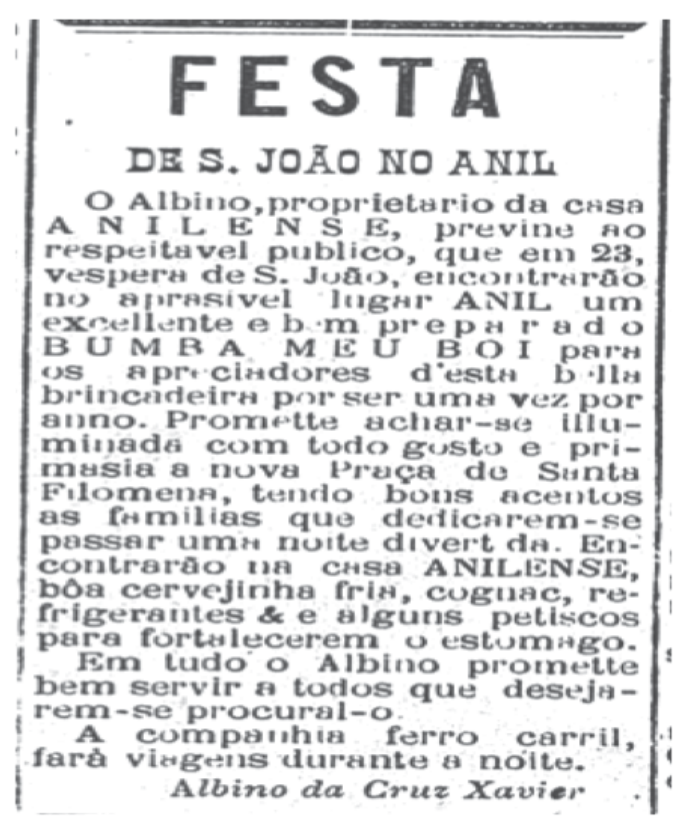

FESTA

\section{DE S. JOÃO NO ANIL}

0 Albino, proprietário da casa ANILENSE, previne ao respeitável público, que em 23, véspera de S. João, encontrarão no aprazivel lugar ANIL um excellente e bem preparado BUMBA MEU BOI para os apreciadores desta bela bella brincadeira por ser uma vez por anno. Promete achar-se iluminada com todo gosto e primasia a nova Praça de Santa Filomena, tendo bons acentos as famílias que dedicarem-se passar uma noite divertida. Encontrarão na casa ANILENSE, boa cervejinha fria, cognac,, refrigerantes $\&$ e alguns petiscos para fortalecerem o estômago.

Em tudo o Albino promette bem servir a todos que desejarem-se procurai-o.

A companhia ferro carril, faráviagens durante a noite.

Albino da Cruz Xavier.

(transcrito conforme a grafia da época)

Fonte: Jornal "Pacotilha", 22 de junho de 1897, Anno XVII - Ed. 145.

Os mediadores tiveram um protagonismo em todo esse processo. Inicialmente, a mediação foi desempenhada por comerciantes que encomendavam a performance a fim de auferir vantagens econômicas. Nesse primeiro momento, a mediação teve o importante papel de estimular o acontecimento do Bumba meu Boi, tornando-o cada vez mais palatável ao público. Com efeito, à medida que a brincadeira era absorvida por um público cada vez maior, mesmo que situado na periferia da sociedade, houve um estímulo para a criação de novos grupos para atender a demanda organizada por mais e mais mediadores. 0 bairro do Anil (bairro periférico; território urbano, rural, industrial e agrícola; espaço de operários e pequenos produtores) foi, inicialmente, o principal palco do Bumba meu Boi. Ao final do século XIX, a dança já estava nas franjas do núcleo principal da capital maranhense. Na primeira metade do 
século XX, foi quebrando a resistência e se aproximando cada vez mais dos espaços anteriormente proibidos, ou seja, do centro da cidade.

Foi justamente nesse contexto que, alegadamente por acaso, gerou-se o que hoje designamos Boi de Orquestra. Esse sotaque, pela proximidade que tem com os modelos da música europeia, com instrumentos usa- dos nas bandas filarmônicas e um tipo de toada mais próxima da canção popular, foi o primeiro sotaque de Bumba meu Boi a ter a audácia de cruzar as fronteiras da zona rural para o interior da urbanidade, apresentando-se perante o palácio do governador em 1948, conforme nota publicada no Diário de São Luiz, de 24 de junho de 1948. Ed. 1045:

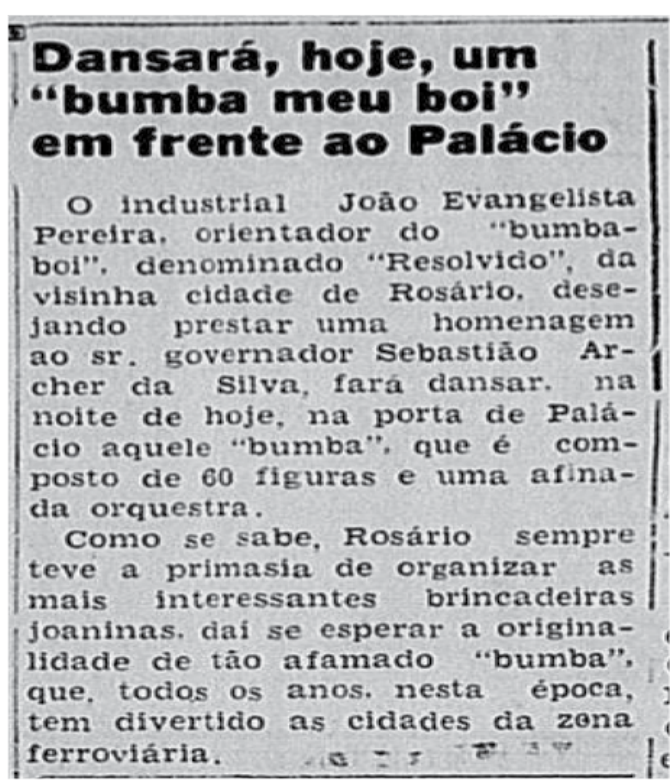

\section{Dansará, hoje, um \\ "bumba meu boi" \\ em Frente ao Palácio}

0 industrial João Evangelista Pereira, orientador do "bumba-boi", denominado "Resolvido", da visinha cidade de Rosário, desejando prestar uma homenagem ao sr. governador Sebastião Archer da Silva, farádansar, na noite de hoje, na porta de Palácio aquele "bumba", que é composto de 60 figuras e uma afinada orquestra.

Como se sabe, Rosário sempre teve a primasia de organizar as mais interessantes brincadeiras joaninas, dai se esperar a originalidade de tão afamado "bumba", que, todos os anos, nesta época, tem divertido as cidades da zona ferroviária.

(transcrito conforme a grafia da época)

Fonte: Diário de São Luiz de 24 de junho de 1948. Ed. 1045.

Posteriormente, essa notícia foi comprovada no trabalho de campo, quando entrevistei o Sr. José Pinheiro dos Santos (nascido em 18/10/1932), conhecido como Pretinho da Noite e brincante do Boi Resolvido desde os dez anos de idade, que confirmou sua participação nesse evento quando tinha 16 anos:
Nós estávamos brincando na porta do Palácio. Quem entrou lá dentro foi só eu. Eu tava com uma sede danada e era pretinho da noite, nessa época. E aí, nós chegamos lá, e eu era um menino, que eu nunca cresci mesmo [...] tinha uns 16 anos mais ou menos [...] aí, nós chegamos no palácio, brincando prá lá e coisa, me deu uma sede, aí, eu entrei por- 
ta adentro. Aí, eu cheguei lá dentro tinha um guarda do lado e do outro e eu fui invadindo. Era muito engraçado que eles nem ligaram mim, né? Foram saber para aonde eu ia. Aí, quando eu cheguei na primeiro salão, no terceiro e no quarto tava um mesa com uns moços, ai eu cheguei e disse: "eh gente me arrume um pouco de água”. Aí o moço foi na geladeira e me deu aquela água e eu tomei, né. Eu tomei, aí, tinha um moço assim, disse: "ta aí meu filho, prá ti”. Do jeito que eu tava alí, era uma pessoa bem enfeitada. Aí ele garrou um dinheiro e me deu. Nesse tempo, dez mil réis era muito dinheiro, era dez milhão de dinheiro. E aí, o pessoal disse: rapaz, Dá Noite foi no governador e ele deu um bocado de dinheiro para ele (informação verbal ${ }^{3}$ ).

Esse momento simbólico se traduziu numa espécie de autorização da performance por parte dos poderes públicos e, consequentemente, na promoção e suporte do Bumba meu Boi. Nesse evento, ocorrido na porta do Poder instituído, o Bumba meu Boi eleito era composto por uma orquestra, o que, para mim, denota o sintomático papel que, aos poucos, o Sotaque de Orquestra vai representar no Maranhão.

Os anos que se seguiram à década de 1960 mostram efetivas ações de regulação por parte das políticas públicas em relação ao Bumba meu Boi. A necessidade de encontrar ícones de brasilidade, instigada pela ditadura militar de 1964 a 1985, levou à criação de inúmeros órgãos que passaram a estudar e a fomentar práticas performativas que pudessem trazer dividendos econômicos e turísticos ao país. Dessa forma, o Bumba meu Boi adquiriu um estatuto particular enquanto representante do Maranhão, tendo sido recontextualizado em função das regras políticas a que deveria se submeter.

0 Estado criou, assim, espaços próprios de âmbito local (arraiais) ${ }^{4}$ e estadual (Anfiteatro da Praça Deodoro, Parque do Bom Menino, Igreja do Santo Antônio, Parque Folclórico da Vila Palmeira, Espaços Vivas) para o desempenho do Bumba meu Boi. Espaços esses que favoreciam, de modo evidente, a apresentação dos grupos de Sotaque de Orquestra. Na verdade, os sotaques mais antigos, Zabumba, Matraca, Baixada e Costa-de-mão, ofereciam um tipo de performance claramente participativa (TURINO, 2008), pois eram grupos comunais, que performavam em seus próprios terreiros ${ }^{5}$ em pagamento de promessas ou por mera diversão, o que não se confınava à apresentação pública em espaço de palco. Diferentemente desses sotaques, o de Orquestra, cujo paradigma de recepção pode ser classificado a partir do que Turino (2008) define como performance apresentativa, ou seja, em um contexto de exposição, de performar para os outros, adaptou-se muito mais rapidamente. Nesse sentido, os grupos de sotaques mais antigos se viram obrigados a adequar sua performance a esse novo modelo de apresentação.

0 Sotaque de Orquestra apresentava uma componente musical baseada na harmonia tonal ocidental, desempenhada por instrumentos de sopro e de corda, a qual, segundo Américo Azevedo ${ }^{6}$, seduziu a cidade:

3. Entrevista realizada pelo autor em 09/07/2014 com o assim chamado Pretinho da Noite.

4. A palavra Arraial designa um espaço preparado especialmente para a realização de festas ou a própria festa.

5. 0 terreiro é um local comunitário próprio para desempenhar a brincadeira de Bumba meu Boi.

6. Américo Azevedo Neto é jornalista, escritor, pesquisador e produtor cultural. 
0 fato de você ouvir a percussão é uma coisa, agora ouvir os instrumentos de sopro, aliás, o instrumento de sopro tem um encanto, uma banda encanta muito mais do que somente uma percussão. 0 instrumento de sopro seduziu a cidade. A cidade tem vontade de dançar quando ouve o Boi de Orquestra (AZEVEDO NETO apud PADILHA, 2014, p. 103).

A agregação dos instrumentistas de sopro, habituados a executar melodias moldadas a partir do sistema tonal, possibilitou um tipo de toada em formato de canção popular. Essas toadas, próximas do gênero musical “"baião”, fazem uso de uma dimensão poética cujo tema procura fazer apologia ao próprio Maranhão no que diz respeito à natureza dos homens e das paisagens do estado. 0 pesquisador e escritor Jomar Moraes ${ }^{7}$ assim se refere às toadas do Boi de Orquestra:

O Boi de Orquestra traz temas que são mais palatáveis, uma linha melódica mais agradável e de mais fácil compreensão. As canções são muito bonitas. Bela Mocidade, de Donato, é algo antológico. É de uma beleza que nenhuma toada dos bois de zabumba e matraca têm. (MORAES apud PADILHA, 2014, p. 99)

Essa componente da performance gerou um corte abissal com os outros sotaques que, respeitando o enredo, usavam toadas que eram praticamente a descrição metoní- mica do próprio enredo que representavam. A poesia dos sotaques de Zabumba, Matraca, Baixada e Costa-de-mão se circunscrevia à narrativa do enredo do Bumba meu Boi, entrecortada por gritos de aboio ${ }^{8}$ que eram incorporados à própria narrativa dramática, enquanto o Boi de Orquestra agregava os instrumentos de sopro, tipicamente europeus, os quais, conforme Américo Azevedo, teriam encantado a cidade, e apresentava um tipo de toada que lembrava o baião, de muito sucesso no nordeste àquela época.

Analisando as matizes rítmicas do baião e do Boi de Orquestra, encontrei muitas similaridades, conforme demonstro abaixo:

Figura 4 - Toques dos instrumentos de percussão no baião

\section{Baiāo}

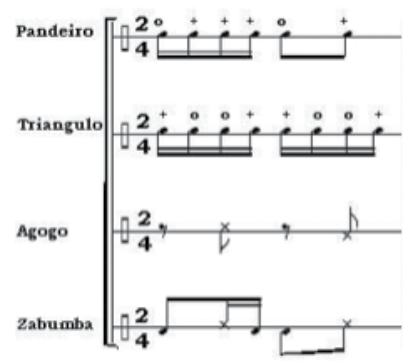

Fonte: http://rafaelmoreira.files.wordpress.com/2011/03/ baic3a303.jpg, 2011.

7. Jomar Moraes é escritor, pesquisador maranhense e advogado. Foi Presidente da Academia Maranhense de Letras, tendo exercido os cargos de Diretor da Biblioteca Pública Benedito Leite e de Secretário de Estado da Cultura do Maranhão, além de Procurador da Universidade Federal do Maranhão.

8. Aboio é um canto típico do nordeste brasileiro e consiste em um canto sem palavras entoado pelos vaqueiros quando estão a conduzir o gado pelas pastagens ou para o curral. 


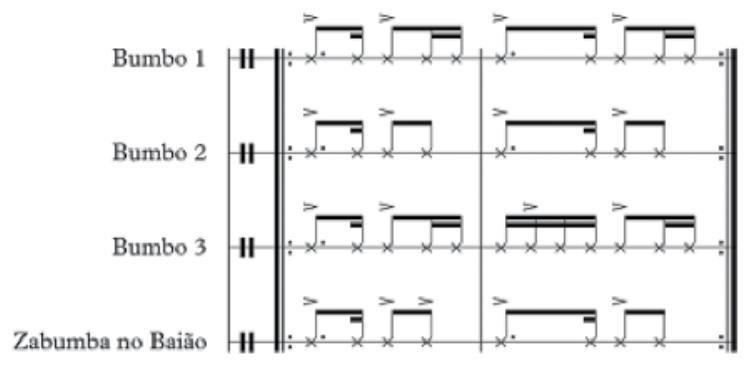

Fonte: Elaboração própria a partir dos registros de campo feitos no dia 26/06/2013.

Figura 6. Toques do bumbo no Boi de Orquestra

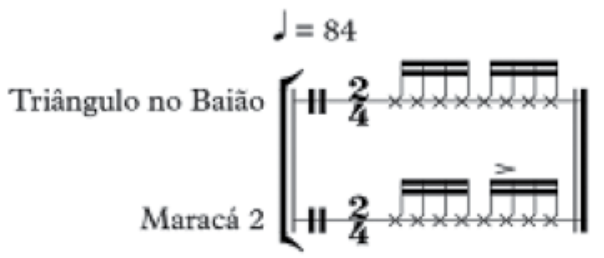

Fonte: Elaboração própria a partir dos registros de campo feitos no dia 26/06/2013.

A execução do Bumbo 2 no Sotaque de Orquestra tem praticamente a mesma execução da zabumba no Baião, assim como a segunda execução do maracá é praticamente idêntica à do triângulo.

Figura 7 - Comparativo dos toques do maracá no Boi de Orquestra e do pandeiro no Baião

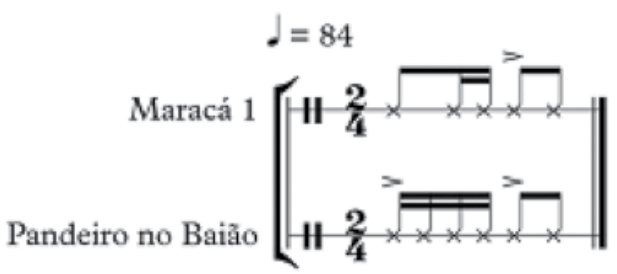

Fonte: Elaboração própria a partir dos registros de campo feitos no dia 26/06/2013.
A primeira execução do maracá no Sotaque de Orquestra tem uma formação rítmica muito parecida com a do pandeiro, sendo que o maracá faz uma colcheia e duas semicolcheias no primeiro tempo, ao passo que o pandeiro faz quatro semicolcheias (como o bumbo 3 no segundo compasso) e, no segundo tempo, ambos fazem duas colcheias. Portanto, evidencia-se que, realmente, a resultante rítmica apresentada pelo Sotaque de Orquestra lembra sobremaneira a panorâmica sonora do Baião.

No que diz respeito à dança, as diferenças também eram significativas. A coreografia ordenada e regrada apresentada pelos grupos de Sotaque de Orquestra, que refletia um modelo de dança de salão europeu em forma de quadrilha, contrastava com as danças dos outros sotaques, que apresentavam um modelo muito próximo de danças das culturas indígena e africana (danças em roda), profundamente participativas, incluindo mesmo os indivíduos que formalmente não integravam os grupos. A transformação do enredo em performance apresentativa gerou, assim, uma evidente dicotomia entre produtores e receptores, distribuídos em dois espaços diferenciados: o palco, confinado aos performers, e as plateias, destinadas ao público. Ademais, 
a ocasião da performance é agora definida por um calendário adaptado às exigências do mercado turístico, espalhado no tempo e divorciado das obrigações devocionais de celebração do São João, em junho, como era no passado.

Com o tempo, como já ficou claro linhas atrás, passou-se do antigo mediador, o particular, para o novo mediador, o Estado. 0 financiamento dos grupos proporcionado pelo Estado é agora uma condição necessária para a concretização da performance tal como ela é imaginada pelos seus mediadores. Essa situação gera uma relação de dependência mútua: os grupos necessitam do Estado para tornar a performance apresentável, e o Estado necessita dos grupos para se fazer representar. Além do mais, coloca-se a decisão nas mãos das próprias autoridades, donas do dinheiro e dos espaços, que agora regulamentam a performance em termos de calendário, forma, tempo de duração, horário e espaço de apresentação, ao mesmo tempo em que atuam como vigilante. Nesse processo de controle, o Estado decide qual Bumba meu Boi pode atuar, quando e como. Através de sua ação, o Bumba meu Boi ascende finalmente a um lugar simbólico de representação, penalizando, todavia, toda a dimensão ritualística (drama) a que estava associado e adquirindo um perfil de espetáculo. 0 folguedo não é mais um momento de catarse dos seus brincantes como forma de libertação da condição de subalternidade colonial, mas se transforma num momento de fruição coletiva, quando, por momentos, parece integrar os diferentes mundos/realidades que povoam o Maranhão.

Por outro lado, a centralidade alcançada define igualmente uma manobra de disfarce. 0 Bumba meu Boi que agora representa o Maranhão guarda as assimetrias sociais e estatutárias que a sociedade maranhense expunha no passado e que permanecem até hoje. Na verdade, o itinerário do Bumba meu Boi, desde a sua condição de prática marginal até o lugar central que ocupa atualmente, aconteceu a partir de processos de recontextualização e de ressignificação, conforme definido por Baumann e Briggs (1990), sempre no sentido de uma aproximação em relação a um modelo desejado. Agora, a expressão de desejo já não é mais do escravo ou do indígena que o enredo alberga, mas antes dos mediadores políticos que aceitam como válido o que permitem integrar ao seu repertório cultural. Os mediadores desejam um Bumba meu Boi que faça justiça à ideia imaginada de um Maranhão povoado de literatos, de poetas e de erudição, em uma tentativa de ressuscitar a “Atenas Brasileira”. O Sotaque de Orquestra responde a esses anseios, pois permite esconder, ainda que por momentos, todo o conflito que o enredo guarda. O Boi de Orquestra canta e dança um Maranhão progressista, voltado para o futuro, fazendo apologia, através de sua narrativa poética, a toda a dimensão de erudição desejada para o Maranhão, esquecendo totalmente o enredo e mantendo apenas os personagens: mãe Catirina, pai Francisco, os índios e o amo, mas sem teatralizar o episódio do dissenso causado pelo pai Francisco.

É claro que o processo de mediação foi mudando de foco com o passar do tempo. Antes, mediava-se para permitir que o boi pudesse performar. Hoje, a mediação se dá para permitir que os grupos de sotaque de Zabumba, considerado o mais antigo e tradicional e o gerador de todos os outros, possa performar, pois a preferência pelo Boi de Orquestra e pelos sotaques da ilha está quase dizimando o Sotaque de Zabumba. Quando exerci o cargo de gestor cultural 
da Fundação Cultural do Maranhão (FUNCMA), entre 1998 e 2002, em uma tentativa de democratizar as escolhas dos grupos de Bumba meu Boi que iriam ser contratados para se apresentar nos arraiais patrocinados pelo Governo do Estado, convoquei os responsáveis por esses espaços e lhes pedi que sugerissem quais os grupos que eles gostariam de ver performando em seus arraiais. Após o recebimento das sugestões, fui procurado pelos representantes dos bois de Sotaque de Zabumba, pois, a partir das indicações feitas pelos representantes dos arraiais comunitários, os grupos que eles representavam só haviam recebido três indicações, enquanto os grupos de orquestras foram solicitados por todos os 23 arraiais. Tive que intervir e mediar a situação. Convoquei os representantes dos arraiais, fiz que vissem a importância de manter os grupos tradicionais e os convenci a receber esses grupos para apresentações nos arraiais que representavam. Era evidente que os Bois de Orquestra estavam assumindo cada vez mais o espaço que outrora cabia aos outros sotaques.

A indústria da música favoreceu também o Sotaque de Orquestra, uma vez que a componente musical desse sotaque, claramente sobreposta a todas as outras dimensões da performance, ao contrário do que ocorre com os outros sotaques, parecia mais adequada ao formato de fixação em disco. As toadas do Boi de Orquestra, em forma de canção, permitem mais facilmente ser recortadas da performance, pois elas sobrevivem como uma unidade emancipada. Embora as primeiras gravações de Bumba meu Boi tenham sido protagonizadas pelos Sotaques de Matraca, Baixada e Zabumba a partir de 1971, é certo que o Sotaque de Orquestra dominou o mercado de discos a partir da década de 1980. Esse processo influenciou igualmente os outros sotaques, que agora procuram adequar-se ao modelo apresentado pelo Sotaque de Orquestra em relação à temática das toadas e à sua duração, não abdicando, porém, de manter uma instrumentação eminentemente percussiva.

Com efeito, o Bumba meu Boi contemporâneo abriga, ainda, uma outra assimetria, referente à sua composição. 0 Sotaque de Orquestra inclui músicos e bailarinos, enquanto os outros sotaques incluem tocadores e brincantes. Os músicos são indivíduos com educação musical formal, o que lhes permite tocar um instrumento enquanto profissionais, e os bailarinos, embora não sejam profissionais, são recrutados através de uma rigorosa seleção que prioriza um modelo estético de ocultação da herança africana do estado do Maranhão. Por outro lado, os tocadores e os brincantes são indivíduos que não necessitam de qualquer educação formal para desempenhar o toque dos tambores ou das matracas, nem estão sujeitos a qualquer tipo de seleção para poderem atuar. Assim, a distinção entre o Boi de Orquestra e os outros sotaques reflete também uma diferença no estatuto social e racial dos membros dos grupos. É fato que nem todos no Maranhão podem ascender à condição de músicos ou de bailarinos e, nesse aspecto - uma vez mais -, o requisito racial é uma variável considerada. 0 Boi de Orquestra, podemos dizer, é um "boi branqueado", branqueamento este que não se vê apenas na cor da pele dos seus membros, mas também no repertório: a dança, a música e a poesia, muito mais próximos dos modelos europeus.

Posso afirmar, portanto, que, sob os seus diferentes aspectos, o Boi de Orquestra é o reflexo de todas as assimetrias sociais que o Maranhão abriga, sendo ele próprio um produto dessas assimetrias. Qualquer outro 
sotaque oferece uma possibilidade de (con) vivência muito mais transversal e inclusiva do que o Sotaque de Orquestra. Esse perfil é visível não só no conjunto de indivíduos que formam os grupos (de caráter mais comunitário, embora a maioria dos seus membros seja proveniente de estratos sociais menos favorecidos economicamente), mas também no tipo de destreza que é pedido a cada um dos integrantes, não implicando qualquer tipo de sofisticação profissional. Os sotaques de Zabumba, Matraca, Baixada e Costa-demão são expressões socialmente mais integradoras, o que, paradoxalmente, torna-as marginais no quadro de uma cultura socialmente estratificada e culturalmente elitista, e é esse mesmo argumento que confere centralidade ao Sotaque de Orquestra.

\section{Como podemos definir, então, o Bumba meu Boi contemporâneo? Como entender o processo histórico que precedeu a sua res- significação?}

O Bumba meu Boi se define a partir de uma constelação de ingredientes com vários níveis de reconhecimento: ,os que identificam a performance para os membros do grupo: a música, a dança, a palavra e o enredo..Por todos esses aspectos, é reconhecido pelos seus atores (os participantes na performance global: membros do grupo e público maranhense), que o distinguem de outras práticas performativas que conhecem. Cada um desses ingredientes tem um significado simbólico e estético, marcado pela história que guarda e pelo simbolismo que representa. 0 fato de o Bumba meu Boi ter se tornado, ao longo dos anos, em uma "ação tornada hábito” (BERGER; LUCKMAN, 2004, p. 66) transformou-o igualmente numa instituição enquanto "tipificação recíproca desempenhada por tipos de atores" (idem).
Assim, o Bumba meu Boi é reconhecido como um representante icônico do Maranhão. Esse reconhecimento é estimulado pelas autoridades políticas que, de alguma forma, utlizam essa manifestação cultural como dispositivo para transacionar uma imagem para o exterior ao mesmo tempo em que o legitimam no interior do próprio estado; permite ainda, ao detentor do poder, a comunicação com o mundo externo e uma interação com o mundo interno e transforma-se, assim, em um capital político que comunica mundos diferentes. Da mesma forma que o Bumba meu Boi passa a ser um mediador entre os seus performers e as autoridades políticas, estas se demarcam da performance, tornando-se atores externos: reconhecem o Bumba meu Boi como seu, mas não se reconhecem nele. Essa ação de dupla institucionalização (a instituição Bumba meu Boi é agora institucionalizada politicamente, tornando-se hábito num contexto de espetáculo) conduz ao estabelecimento de hierarquias e coloca em primeiro plano um tipo de Bumba meu Boi que se diferencia dentro dos diferentes sotaques pelo modo como se aproxima de um modelo estético menos vinculado às práticas locais, tornando-se mais cosmopolita e mais próximo, portanto, daquele que hoje é adotado pelos mediadores e pela classe política letrada e de formação alegadamente europeia. Aqui, me refiro ao Sotaque de Orquestra.

Nesse processo de transição e de consequente transformação, o Bumba meu Boi é como que eruditizado a partir de um modelo que está, em primeiro lugar, na música (a orquestra), e que é depois estendido às outras componentes da performance. Os atores desse Bumba meu Boi, ou do Boi de Orquestra, incorporam agora elementos que pertencem também ao universo social das 
classes dominantes, que agora aceitam a performance e se reconhecem nela.

Consequentemente, os outros sotaques se adequam agora ao modelo do Boi de Orquestra, priorizando toda a dimensão performativa de apresentação e sancionando sua componente participativa (TURINO, 2008). 0 enredo, em que a história social do Bumba meu Boi está guardada, é agora diluído e silenciado em função de outras prioridades que oferecem ao Bumba meu Boi a oportunidade de transpor as fronteiras da subalternidade. Porém, essa nova condição é apenas ilusória. A ressignificação do Bumba meu Boi não se faz sem a efetiva penalização de toda a história social de resistência que guarda e que o transformava, no passado, em um lugar de catarse e de crítica aos poderes dominantes. De fato, a ressignificação do Bumba meu Boi não faz mais do que reiterar o poder de uma ordem social instituída que necessita dos seus lugares marginais para garantir a centralidade das elites. A elite dominante aceita o Bumba meu Boi, desde que modificado em função de seu modelo estético.

A música foi decisiva nesse processo. Através dela, o Bumba meu Boi, representado pelo Boi de Orquestra, foi finalmente aceito enquanto prática autorizada no Maranhão, mas foi também a música que ofereceu aos mediadores a possibilidade de garantir o controle e a vigilância necessários para que continuasse a ser respeitada a ordem social por eles desejada. A institucionalização do Bumba meu Boi como ícone do Maranhão e patrimônio imaterial do Brasil é, na verdade, a materialização de uma impossibilidade: reverter a ordem so- cial que o Bumba meu Boi testemunha no seu enredo. Nesse sentido, a recontextualização e ressignificação desse folguedo não é mais do que uma construção ilusória da realidade onde a música configura o mais importante dispositivo de controle.

0 espaço social se modifica mais lentamente no Maranhão do que o tempo físico, que avança, passa, corre, mas sem implicar grandes impactos na qualidade de vida da ampla maioria da população que ali reside, vive e se manifesta através de folguedos populares. É nesse terreiro social e político que o Bumba meu Boi se apresenta todos os anos para fazer a festa e ser enaltecido como representante simbólico do folclore regional e como patrimônio imaterial brasileiro, para orgulho dos seus protagonistas e aproveitamento de sua classe dominante. É nesse momento que dominadores e dominados se aproximam, como se nessas plagas se formasse um cordão unido por uma igualdade que, no dia a dia, não se consubstancia, pois cada classe social sabe exatamente o papel que lhe cabe: ou de amo, ou de pai Francisco, ou de Pajé, ou de mãe Catirina, ou de caboclo de pena, ou de músico, ou de mutuca9 ${ }^{9}$ ou de simples observador passivo da performance que desfila na passarela da Cultura Popular do Maranhão. Dessa forma, o Bumba meu Boi, quer no passado quer no presente, constitui um dispositivo de separação absolutamente necessário para a consolidação do que Rancière (2006) designa como "mundo comum". Estamos reunidos, mas não nos confundimos. Estamos juntos, mas não unidos. Estamos perto, na brincadeira, mas distantes na seriedade do cotidiano.

9. Mutuca é como são chamadas as mulheres (esposas, amantes, namoradas) que acompanham os brincantes, ajudando-os a carregar as indumentárias e lhes conduzir para casa quando do término da performance, pois muitos deles estão tão embriagados que podem não reconhecer o caminho de casa. 


\section{Referências}

ARENDT, H. A condição humana. 10 ed. Rio de Janeiro: Forense Universitária, 2007.

AZEVEDO NETO, A. Bumba boi no Maranhão. $2^{\mathrm{a}}$ ed. São Luís: Alumar, 1997.

BAUMAN, R.; BRIGGS, C. L. Poetics and Performance as Critical Perspectives on Language and Social Life, Annual Review of Anthropology. Annual Reviews Stable. v. 19, p. 59-88. Disponivel em: ,http://www.jstor.org/stable/2155959. Acesso em: 25 ago. 2013.

BERGER, P. L.; LUCKMANN, T. A Construção Social da Realidade. 23a ed. Petrópolis: Vozes, 2003.

CONQUERG00D, D. Performance Studies: Interventions and Radical Research. The MIT Press Stable. Author(s): Source: TDR (1988), Vol. 46, No. 2 (Summer, 2002), pp. 145-156, Disponivel em: $<$ http://www.jstor.org/stable/1146965>. Acesso em 8 out. 2013.

CORRÊA, J. R. C. Formação social do Maranhão: o presente de uma arqueologia. 1982. Dissertação (Mestrado)-PIMES/UFPE, Recife, 1982.

DIÁRIO DE SÃO LUIZ. 24 de junho de 1948. Ed. 1045.

DIÁRIO DO MARANHÃO. 25 de agosto de 1876. Ed.915, Anno VII.

MIGNOLO, W. D. The Darker Side of the Renaissance. Michigan: The University of Michigan Press, 2001.

PACOTILHA. 22 de junho de 1897, Anno XVII. Ed. 145.

PADILHA, A. F. S. A Construção Ilusória da Realidade, a Ressignificação e Recontextualização do Bumba meu Boi do Maranhão a partir da Música. 2014. Tese (Doutorado em Etnomusicologia), Universidade de Aveiro, Aveiro-Portugal, 2014.

RANCIĖRE, J. Crítica da razão - dissenso. p. 367-382. Rio de Janeiro: FUNARTE, p.365-382, 1996/2006.
TOCANDO Baião. Blog do Rafael. Disponível em: <http://rafaelmoreira.files.wordpress. com/2011/03/baic3a303.jpg >. Acesso em: 25 ago. 2013.

TURINO, T. Music as Social Life. The politics of participation. Chicago: The University of Chicago Press, 2008.

TURNER, V. The anthropology of performance. New York: PAJ Publications, 1987.

TURNER, V. Dramas, Campos e Metáforas. Niterói (RJ): Eduff, 1974.

TURNER, V. 0 Processo Ritual. Petrópolis (RJ): Vozes, 1974. 
RESUMO

Trabalho de pesquisa sobre o processo de Construção Ilusória da Realidade, destacando o Bumba meu Boi enquanto prática performativa, inicialmente marginal e, posteriormente, ressignificada e recontextualizada a partir da música. Análise dessa prática performativa enquanto um lugar político e de ocultação de uma outra condição de subalternidade e manutenção da assimetria social existente no Maranhão.

PALAVRAS-CHAVE

Festa. Ritos. Religiosidade popular. Memória. Subalternidade. Pós-colonialismo.

\section{ABSTRACT}

Research work about the process of Illusory construction of Reality, highlighting the Bumba-meu-Boi as an initially marginalized performative practice, later resignified and recontextualized trough music. Analysis of this performative practice as a political space and mean of concealing another condition of subordination and maintenance of existing social asymmetry in Maranhão.

\section{KEYWORDS}

Party. Rites. Popular religiosity. Memory Subordination. Postcolonialism. 
